\title{
Trials for Gathering Information on an Unknown Peak in the GC-MS Spectra of Horse and Pony Hair Extracts
}

\author{
Maia Tsikolia1,2* (D), Till Opatz ${ }^{3}$ (D), Ulrich Kauhl ${ }^{3}$ (D), Nurhayat Tabanca4 ${ }^{4}$, Betul Demirci ${ }^{5}$ (D), \\ Saundra H. TenBroeck ${ }^{6}$ (), Kenneth J. Linthicum ${ }^{1}$ (i), Ulrich R. Bernier ${ }^{1 *}$ (1) \\ ${ }^{1}$ US Department of Agriculture-Agricultural Research Service (USDA-ARS), Center for Medical, Agricultural, and Veterinary \\ Entomology (CMAVE), Gainesville, FL, USA \\ ${ }^{2}$ Nichbisi Scientific Research Center (NSRC), Mtskheta, Georgia \\ ${ }^{3}$ Institute of Organic Chemistry, University of Mainz, Mainz, Germany \\ ${ }^{4}$ US Department of Agriculture-Agricultural Research Service (USDA-ARS), Subtropical Horticulture Research Station (SHRS), \\ Miami, FL, USA \\ ${ }^{5}$ Department of Pharmacognosy, Faculty of Pharmacy, Anadolu University, Eskisehir, Turkey \\ ${ }^{6}$ University of Florida's Institute of Food and Agricultural Sciences (UF/IFAS) Horse Teaching Unit, Gainesville, FL, USA \\ Email: ^m.tsikolia@gmail.com, *ubernier@cox.net
}

How to cite this paper: Tsikolia, M., Opatz, T., Kauhl, U., Tabanca, N., Demirci, B., TenBroeck, S.H., Linthicum, K.J. and Bernier, U.R. (2021) Trials for Gathering Information on an Unknown Peak in the GCMS Spectra of Horse and Pony Hair Extracts. Advances in Entomology, 9, 100-111. https://doi.org/10.4236/ae.2021.92009

Received: February 22, 2021

Accepted: April 25, 2021

Published: April 28, 2021

Copyright (C) 2021 by author(s) and Scientific Research Publishing Inc. This work is licensed under the Creative Commons Attribution-NonCommercial International License (CC BY-NC 4.0). http://creativecommons.org/licenses/by-nc/4.0/ (c) (i) (\$) Open Access

\begin{abstract}
The volatile compounds from horse and pony hairs and skin were analyzed to determine bioactive molecules that are kairomones used for host location by blood-feeding diptera. In this study, horse and pony hair samples were extracted with organic solvents (pentane or hexane) and analyzed by gas chromatography-mass spectrometry analysis (GC-MS) with closed electron ionization (CEI). Using the GC-MS analysis, we observed a compound peak, which could not be identified by comparison to mass spectra in the mass spectral library. This unknown compound was often the largest peak in the chromatogram and had a retention index and mass spectral fragmentation similar to nonanal. However, there were several differences in the fragmentation pattern. When compared to a nonanal reference standard, it was evident that this was a different compound. Hydrodistillation of pony hair was another extraction method to obtain the unknown component in higher concentrations. Analysis of this extract with GC-flame ionization detector (FID) with GC-MS confirmed the same unknown peak. Further experiments and analysis with the various mass spectroscopy tools gave the possible molecular ion with mass-to-charge ratio $(m / z) 142$, corresponding to the unknown component.
\end{abstract}

\section{Keywords}

Nonanal, Skin Emanation, Insect Pests, Equus caballus, Equus ferus caballus, 
Mass Spectroscopy, Structure Elucidation

\section{Introduction}

Blood-feeding diptera such as stable flies, Stomoxys calcitrans (L.), horse flies, Tabanus spp. and Hybomitra spp., as well as deer flies, Chrysops spp., can cause irritation and distress in mammals [1]. Tabanid flies impact mammals via transmission of disease, reduced weight gains in animals and annoyance [2].

Mammalian sebum (secretions from the skin surface of mammals) contains an array of compounds possessing unusual unsaturation sites, chain lengths, and branching patterns [3]. The hydrolysis products on some mammalian (human, rat, rabbit, mouse, sheep, guinea pig etc.) skin surfaces include squalene, sterols, monohydric alcohols, alkane-1,2-diols, $\boldsymbol{\alpha}$ - and $\omega$-hydroxy acids [4]-[9], and unhydrolyzed products: squalene, free sterols, sterol monoesters, monoester waxes, diester waxes (type I and II), glyceryl ether diesters, triglycerides and free fatty acids [10] [11] [12] [13]. Chatt and Katz [14] identified free fatty acids, monoglycerides, diglycerides, triglycerides, wax esters, hydrocarbons, and alcohols from the hair. A study of the chemical composition of 20 different mammalian species showed a uniqueness of the sebum composition for each species, although there were similarities within genera, e.g., intermediates of cholesterol biosynthetic pathway; variety of mono- and diesters, typically, containing unusual fatty acids [15] [16], identified anteiso-branched 18-methyl-eicosanoic acid (MEA), comprising approximately $40 \%$ of the total fatty acids in the integral lipid fraction in mammalian hair. Additionally, cholesterol sulphate and ceramides were identified. Chemical analyses of the mammalian pelage have focused on the even-toed ungulates (Cetartiodactyla), chiefly on bovids [17] [18]. Analyses of the pelage chemistry of odd-toed ungulates (Perissodactyla) are confined to the domestic horse (Equus caballus) and other equids. These studies revealed giant $\left(\mathrm{C}_{28}-\mathrm{C}_{36}\right)$ lactone rings of $\omega$-hydroxy acids, known as equolides, among horses, asses, and zebras [19]. Scott and Miller [20] reported that freshly liberated sebum contains triglycerides and wax esters in the hair follicles which becomes contaminated with lipase-producing bacteria (Staphylococcus spp.), as well as linoleic, myristic, oleic and palmitic acids. The structure of sterols and fatty acids are speciesspecific, thus, the molecular composition can serve as a fingerprint for the species; e.g. only surface lipids for Equidae contain lactones (about $47 \%$ of the total), and sterol esters, cholesterol and wax diesters. Nicolaides, Fu and Rice [21] identified icosane and cholesteryl acetate on horse skin surface. In the skin surface lipids from the sides of male and female horses (E. caballus), Downing and Colton [22] identified cholesterol, cholesteryl esters and the lactones of $\omega$-hydroxy acids, each including a methyl group in the $\mathrm{n}-1$ position, mostly mono-unsaturated ( $\mathrm{n}-8$ or $\mathrm{n}-10)$, but, also, with small amounts of saturated and dienoic species. Ferreira et al. [23] identified predominantly ethyl octanoate, ethyl deca- 
noate, and, as minor components, hexanal, heptanal, and (E)-2-decenal in horse extracts. According to Wertz [24] the $\omega$-hydroxy acids that are products from the hydrolysis of horse lactones from the common horse (E. caballus) are mostly monounsaturated, iso-branched and have 33-, 35- and 37-carbons in the major compounds.

To identify components responsible for the attraction of flies and other insects to horses, we investigated horse hair volatiles/extracts. Gas chromatographymass spectroscopy (GC-MS) analysis led to the discovery of an unknown compound. It was the most abundant peak in the chromatogram. This compound was not detected in similar analyses of dog and donkey hair extracts; however, it was observed in the hair extract from a pony. To the best of our knowledge, the peak observed in our study has not been reported previously according to the existing literature. This report details our attempt to identify the unknown compound in horse and pony hairs.

\section{Materials and Methods}

Horse and pony hairs were obtained on 03/17/2016 from the University of Florida's Institute of Food and Agricultural Sciences (UF/IFAS) Horse Teaching Unit, Gainesville, FL, USA. After the horse and pony had been groomed, hairs were sealed in glass bottles and stored in a freezer. For the extraction, pentane, $n$-hexane, dichloromethane $\left(\mathrm{CH}_{2} \mathrm{Cl}_{2}\right)$, acetone, ethyl acetate (EtOAc), ethanol were used. All solvents and neat nonanal as a reference standard (CAS \# 124-19-6) were purchased from Sigma-Aldrich, St. Louis Corp., MO, USA.

\subsection{Extraction}

\subsubsection{Solvent Extraction for Horse and Pony Hairs (Sample 1)}

Horse or pony hair $(0.3 \mathrm{~g})$ was placed in a $15 \mathrm{~mL}$ centrifuge tube, pentane ( 7 $\mathrm{mL}$ ) was added. The tube was then stored in a refrigerator for 3 days, after which the tube was shaken (30 min, Excella E2 Platform shaker, New Brunswik Scientific, North Hampton, NH, USA), vortexed (30 sec, Genie 2 Vortex mixer 12-812, Fisher Scientific, Hampton, NH, USA), filtered (Whatman qualitative filter paper, Grade 1, diam. 90 mm, Sigma-Aldrich Corp., St. Louis, MO, USA), and dried $\left(\mathrm{Na}_{2} \mathrm{SO}_{4}\right)$. An aliquot of $2 \mathrm{~mL}$ was filtered using a syringe filter $(0.45 \mu \mathrm{m}$, Minisart SRP, Sartorius Stedim Biotech GmbH, Göttingen, Germany). This procedure was repeated using solvents: $n$-hexane, $\mathrm{CH}_{2} \mathrm{Cl}_{2}$, acetone, EtOAc, and ethanol.

\subsubsection{Hydrodistillation of Pony Hair (Sample 2)}

A sample of pony hair $(150 \mathrm{~g})$ was hydrodistilled for $3 \mathrm{~h}$ in a Clevenger-type apparatus (Fisher Scientific, Hampton, NH, USA). After 3 h, the hydrosol was collected and extracted three times with $100 \mathrm{~mL}$ of $n$-hexane at room temperature. The organic layer was dried over anhydrous sodium sulfate, evaporated using a rotary evaporator producing $12 \mathrm{mg}$ of extract and stored in a dark glass bottle at $4^{\circ} \mathrm{C}$ for subsequent analysis. The hydrodistillate was used for derivati- 
zation, as well.

\subsection{Spectroscopy Methods}

2.2.1. Gas Chromatography-Mass Spectrometry Analysis (GC-MS) with Closed Electron Ionization (CEI), Negative Ion Chemical Ionization (NICI), and Positive Ion Chemical Ionization (PICI)

A $1 \mu \mathrm{L}$ aliquot from each extract was analyzed along with the pentane blanks using a ThermoFinnigan DSQ (Thermo Fisher Scientific; Austin, TX) gas chromatograph (GC) equipped with a DB-5 (Agilent; Santa Clara, CA) column (30 m $\times 0.25 \mathrm{~mm}$ ID; $0.25 \mu \mathrm{m}$ film thickness). The GC oven temperature program was set at an initial temperature of $50^{\circ} \mathrm{C}$ and held at that temperature for 5 min post injection ramped at $3^{\circ} \mathrm{C} / \mathrm{min}$ to $240^{\circ} \mathrm{C}$ and held $5 \mathrm{~min}$ at the same temperature. The mass analyzer was scanned at a rate of $0.5 \mathrm{sec}$ over a mass range of $m / z 35$ to $\mathrm{m} / z$ 650. The programmed temperature vaporizing (PTV) injection port was operated from $50^{\circ} \mathrm{C}$ to $240^{\circ} \mathrm{C}$ with a rate of $14.5^{\circ} \mathrm{C} / \mathrm{sec}$, in splitless mode, the transfer line temperature was set to $200^{\circ} \mathrm{C}$, and the carrier gas was set to a constant flow of $1.5 \mathrm{~mL} / \mathrm{min}$. CEI-MS Spectra were recorded at $70 \mathrm{eV}$ electron energy. Reagent gas flow was set at $0.3 \mathrm{~mL} / \mathrm{min}$ for CEI and $2.5 \mathrm{~mL} / \mathrm{min}$ for NICI and PICI. Tune files were used accordingly for CEI, NICI and PICI.

Derivatization with the acetic anhydride: Pony hair hydrodistillate (sample $2,12 \mathrm{mg})$ was dissolved in chloroform $(10 \mathrm{~mL})$. Acetic anhydride $(1 \mathrm{~mL})$ and acetic acid $(2 \mathrm{~mL})$ were added and heated at $50^{\circ} \mathrm{C}$ for $16 \mathrm{~h}$ [25]. Then mixture was washed with water $(10 \mathrm{~mL})$ and brine $(10 \mathrm{~mL})$. The mixture was concentrated under vacuum to dryness and redissolved in chloroform for analysis by CEI-GC-MS.

Identification: The analysis was carried out by comparison of the chromatographic peak retention indices to those of possible candidates, against standard compounds when available and by comparison with literature data. Comparisons of MS fragmentation patterns with those of standards and mass spectrum database search were performed using the Wiley GC-MS library (Wiley, New York, NY, USA), the NIST library (US National Institute of Standards and Technology, Gaithersburg, MD, USA) and the Adams Library [26]. Reference points to calculate the arithmetic retention indices (AI) [26] at CEI tune were generated by $n$-alkanes.

\subsubsection{Gas Chromatography-Flame Ionization Detector (FID) and Gas Chromatography-Mass Spectrometry Analysis (GC-MS) with Electron Impact (EI) Ion Source}

GC Analysis: The GC analysis was carried out using an Agilent 6890N GC system. The FID detector temperature was $300^{\circ} \mathrm{C}$. To obtain the same elution order with GC-MS, simultaneous auto-injection was done as a duplicate on the same column applying the same operational conditions. Relative percentage amounts of the separated compounds were calculated from FID chromatograms.

GC-MS Analysis: An Agilent 5975 GC-MSD system was used, where Innowax FSC column $(60 \mathrm{~m} \times 0.25 \mathrm{~mm}, 0.25 \mu \mathrm{m}$ film thickness $)$ was used with he- 
lium as carrier gas $(0.8 \mathrm{~mL} / \mathrm{min})$. The $\mathrm{GC}$ oven temperature was kept at $60^{\circ} \mathrm{C}$ for $10 \mathrm{~min}$ and programmed to $220^{\circ} \mathrm{C}$ at a rate of $4{ }^{\circ} \mathrm{C} / \mathrm{min}$, and kept constant at $220^{\circ} \mathrm{C}$ for $10 \mathrm{~min}$ and then programmed to $240^{\circ} \mathrm{C}$ at a rate of $1^{\circ} \mathrm{C} / \mathrm{min}$. The split ratio was adjusted at $40: 1$. The injector temperature was set to $250^{\circ} \mathrm{C}$. Mass spectra were recorded at $70 \mathrm{eV}$, where the mass range was from $\mathrm{m} / \mathrm{z} 35$ to 450 .

Identification: The analysis of the unknown peak (sample 2) was accomplished by comparison of the relative retention time (RRT) with those of authentic samples or by comparison of their relative retention index (RRI) to series of $n$-alkanes [27]. Computer matching against commercial (Wiley GC/MS Library, MassFinder Software 4.0) [28] [29] [30] and in-house "Baser Library of Essential Oil Constituents" built up by genuine compounds and components of known oils was used for the identification.

\subsubsection{Accurate Electrospray Ionization Mass Spectroscopy (ESI-MS) and} Liquid Chromatography Mass Spectroscopy (LC-MS)

Accurate masses were measured at the Mass Spectrometry Facility of the Department of Chemistry, University of Florida; ESI-MS was performed using a 6210 TOF-MS (Agilent Technologies) equipped with an electrospray ionization source. Samples were dissolved in dichloromethane and solutions introduced via direct injection. LC-MS was performed using a Thermo Gold C18 column with a gradient going from $100 \%$ water with $0.1 \%$ formic acid to $95 \%$ methanol with $0.1 \%$ formic acid over the course of 35 minutes. An extracted ion chromatogram (EIC) was taken from the total ion chromatogram (TIC) at $m / z$ values of 142 .

\section{Results and Discussion}

\subsection{Extraction}

During our search for new natural products with attractant or repellent activity against blood-feeding arthropods, we observed a peak consisting of an unknown compound in horse hair extract. Solvent extraction (sample 1) using pentane was conducted for both horse and pony hair samples. Extracts using $n$-hexane, $\mathrm{CH}_{2} \mathrm{Cl}_{2}$, acetone, EtOAc, ethanol were conducted using horse hair, however, pentane or hexane were selected the best extraction solvents since the peak of interest was most abundant compared to other solvent extracts. For further investigation, the hydrodistillation method (sample 2) was conducted only for the pony hair sample, because there was sufficient material for the hydrodistillation. During distillation, volatile compounds dissolved in the hydrosol. After the distillation process, the hydrosol was collected, extracted with $n$-hexane and, subsequently, this $n$-hexane extract was used for analysis. Both methods gave the peak of interest. The peak intensity decreased over time (one year) by from $60 \%$ - $70 \%$ to approximately $2 \%$ despite being stored in a freezer at $-20^{\circ} \mathrm{C}$. The following data detail the efforts made to identify this unknown compound present in samples 1 and 2 using the various mass spectroscopy techniques. 


\subsection{Spectroscopy}

\subsubsection{Analysis by GC-MS}

CEI-GC-MS Spectroscopy of the extracts (samples 1 and 2) using a polar GC column showed the unknown peak at retention time $(\mathrm{RT} \sim 15.76 \mathrm{~min}, \mathrm{AI}=1067)$. From the mass spectral library, this peak matched nonanal with a match score of 820 (out of 1000) and high probability (>80\%). When compared with the authentic nonanal standard, the fragmentation pattern and the retention time were close, but not identical to that of nonanal (RT $17.61 \mathrm{~min}$ ) (Figure 1). The AI for nonanal is 1100 compared to 1067 for the unknown peak. The mixed injection of the horse/pony hair extract and nonanal, also, showed that the unknown peak does not correspond to nonanal. GC-MS analysis with NICI and PICI modes gave the mass-to-charge ratios $(\mathrm{m} / \mathrm{z})$ of $141(\mathrm{M}-1)$ and $143(\mathrm{M}+1)$, correspondingly (Figure 2). Accordingly, we assumed that the mass of the molecular ion for the unknown component should be 142 . To verify our assumption, the hydrodistillate (sample 2) was derivatized with acetic anhydride and analyzed by CEI-GC-MS method. At $26.86 \mathrm{~min}$, a new peak was detected with $\mathrm{m} / \mathrm{z}=184\left[\sim \mathrm{M}+\mathrm{COCH}_{2}\right]$, which could correspond to the sum of the mass ratios for the unknown component $(m / z=142)$ and ketene $(m / z=42)$ (Figure 3$)$.

\subsubsection{Analysis by GC-FID and GC-MS}

GC-FID And GC-MS using a polar column was also used to investigate the unknown peak. The compound of interest was present in both samples (1 and 2) with the RRI $=1550$, and \% calculated from FID data: EIMS, $70 \mathrm{eV}, \mathrm{m} / \mathrm{z}$ (rel. int.): 124 (12), 109 (34), 95 (48), 85 (29), 82 (60), 69 (72), 57 (100), 43 (88) (Figure 4). However, the compound cannot be identified by commercially available mass spectral libraries, and in house "Baser Library of Essential Oil Constituents" library.

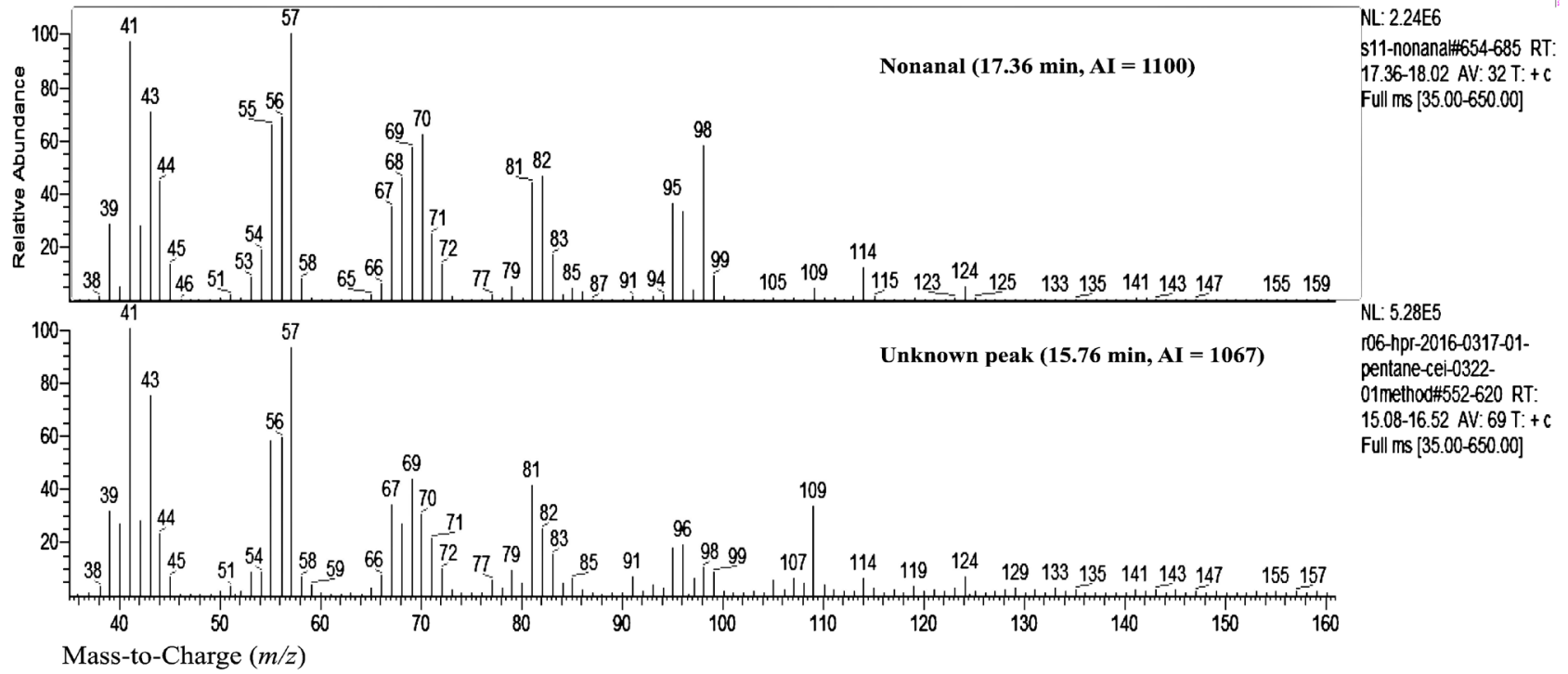

Figure 1. CEI-GC-MS spectrum for nonanal $(\mathrm{AI}=1100, \mathrm{RT} \sim 17.36$ min, neat compound $)$ and unknown peak $(\mathrm{AI}=1067, \mathrm{RT} \sim$ $15.76 \mathrm{~min}$ ). 


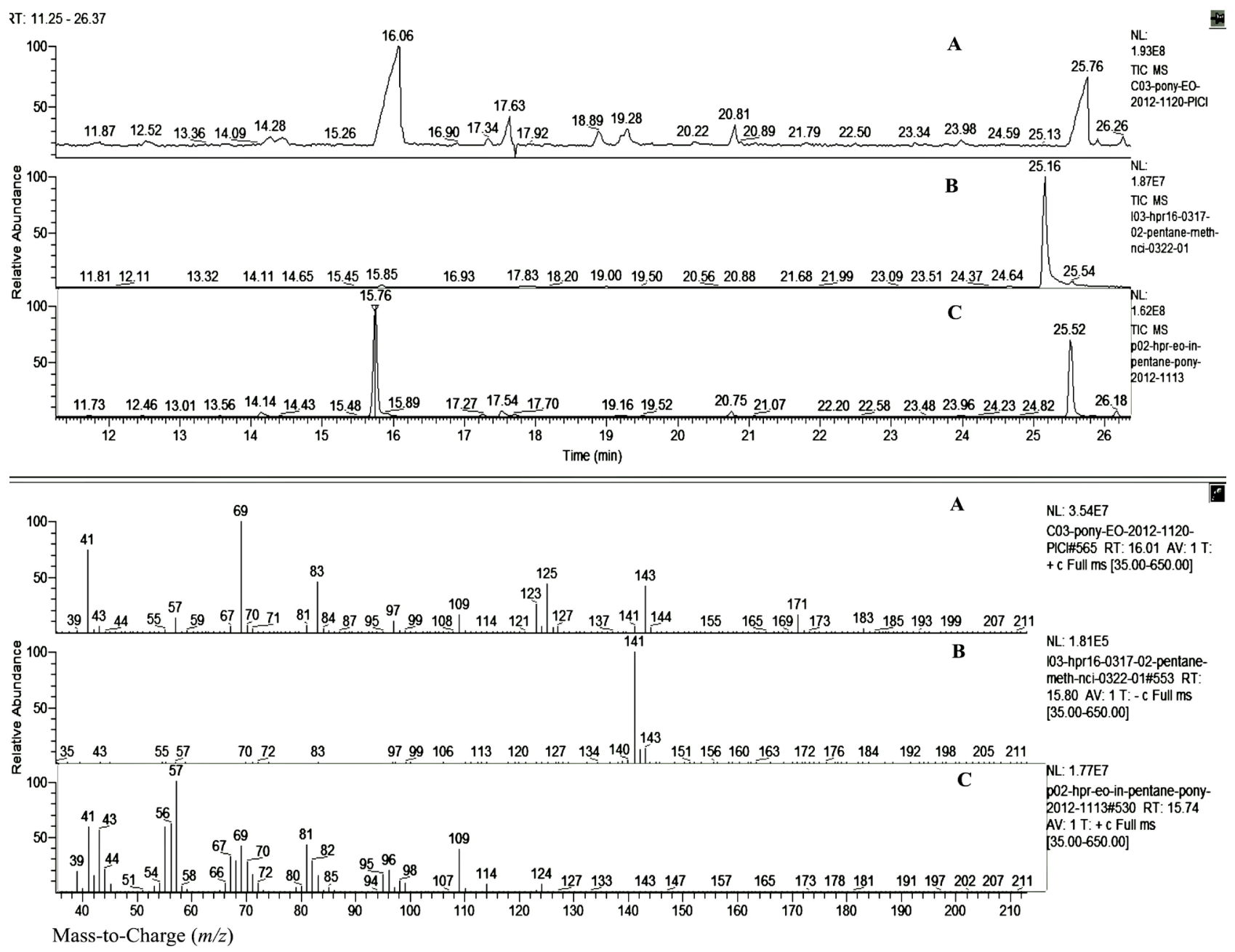

Figure 2. Comparison of (A) PICI-, (B) NICI- and (C) CEI-GC-MS methods for the unknown component at AI = 1067 (RT 15.76).
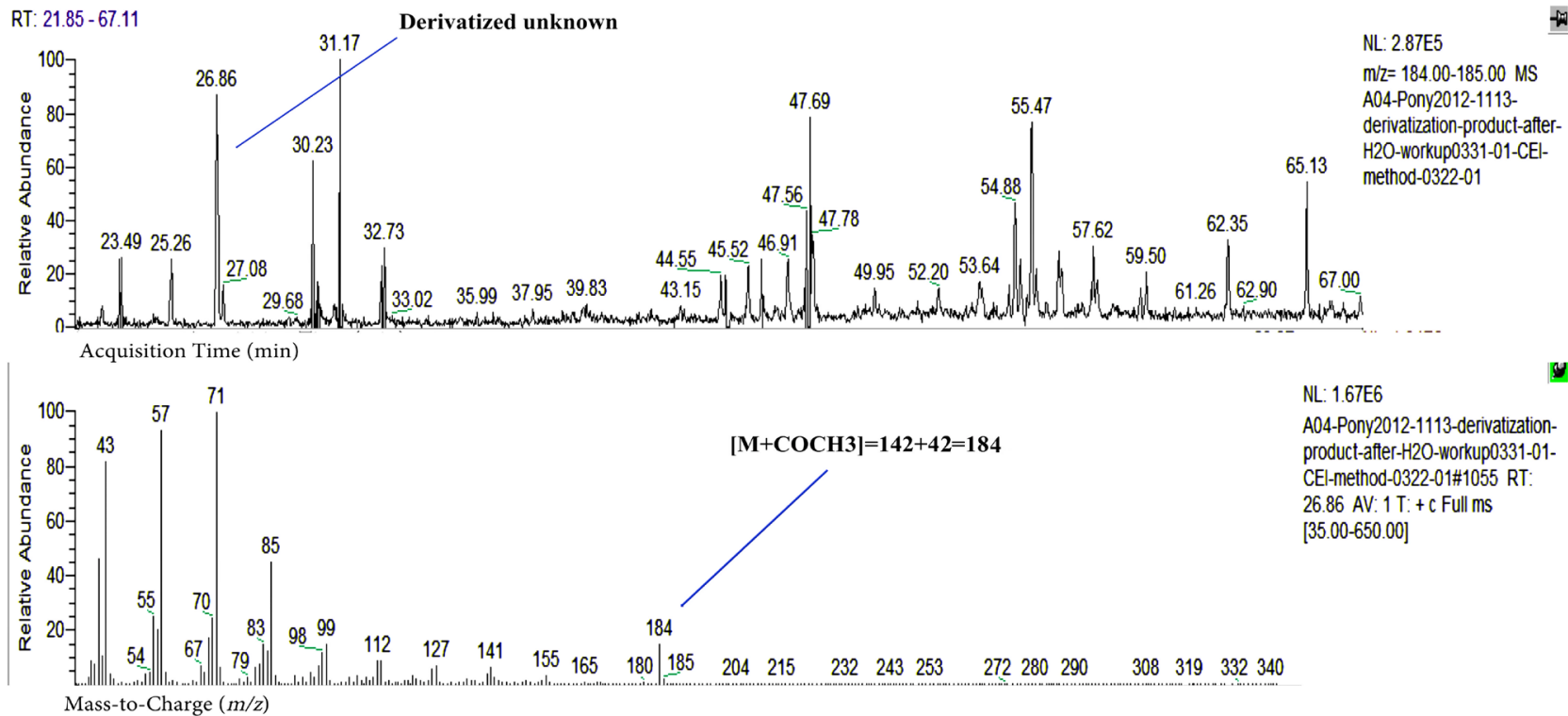

NL: $1.67 E 6$

A04-Pony2012-1113-derivatizationproduct-after-H20-workup0331-01-

CEl-method-0322-01\#1055 RT

26.86 AV: $1 \mathrm{~T}:+\mathrm{c}$ Full ms

[35.00-650.00]

Figure 3. CEI-GC-MS Spectra for the derivatized mixture of the pony hair hydrodistillate. 


\subsubsection{Analysis by ESI-MS and LC-MS}

To further investigate the unknown peak, the extracts were analyzed by high resolution ESI-MS and LC-MS. By accurate ESI-MS spectra (without prior HPLC separation for apparative reasons) the masses related to the molecular ion of unknown were observed (Figure 5). There were several species with a nominal mass of $142-143$ and they differ slightly in their exact mass, but 142.1595 was the most intense of them, followed by 143.1510 .

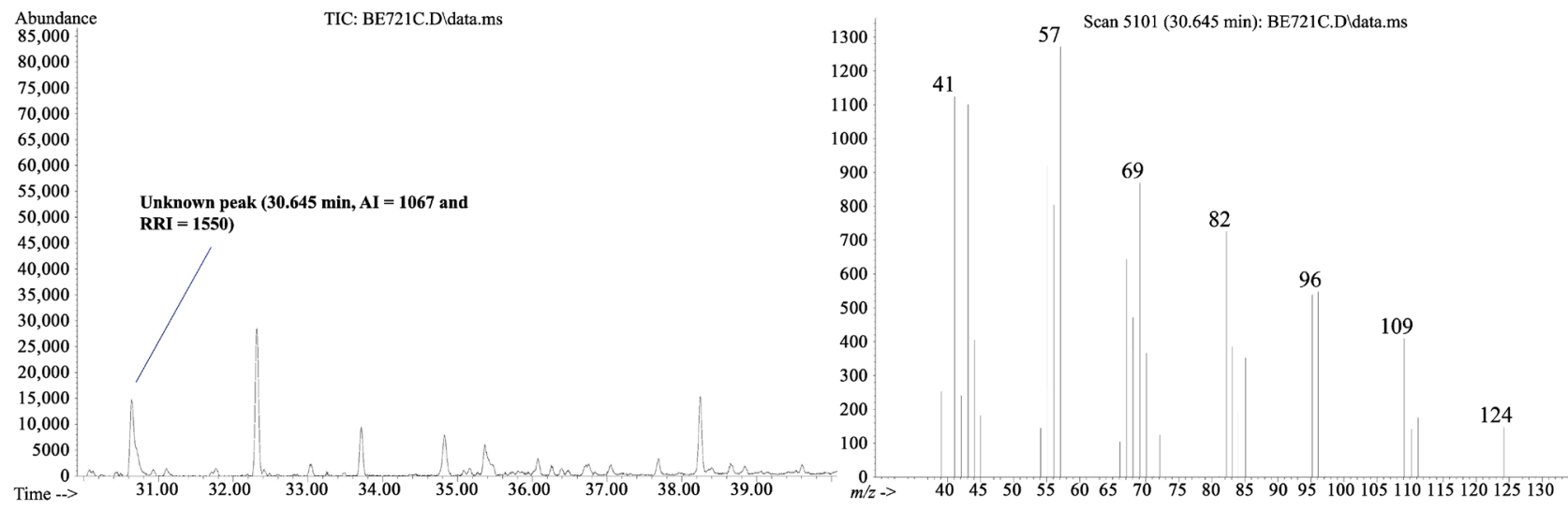

Figure 4. TIC Chromatogram with GC-MS spectrum for compound of interest at $\mathrm{AI}=1067$ and RRI $=1550$.

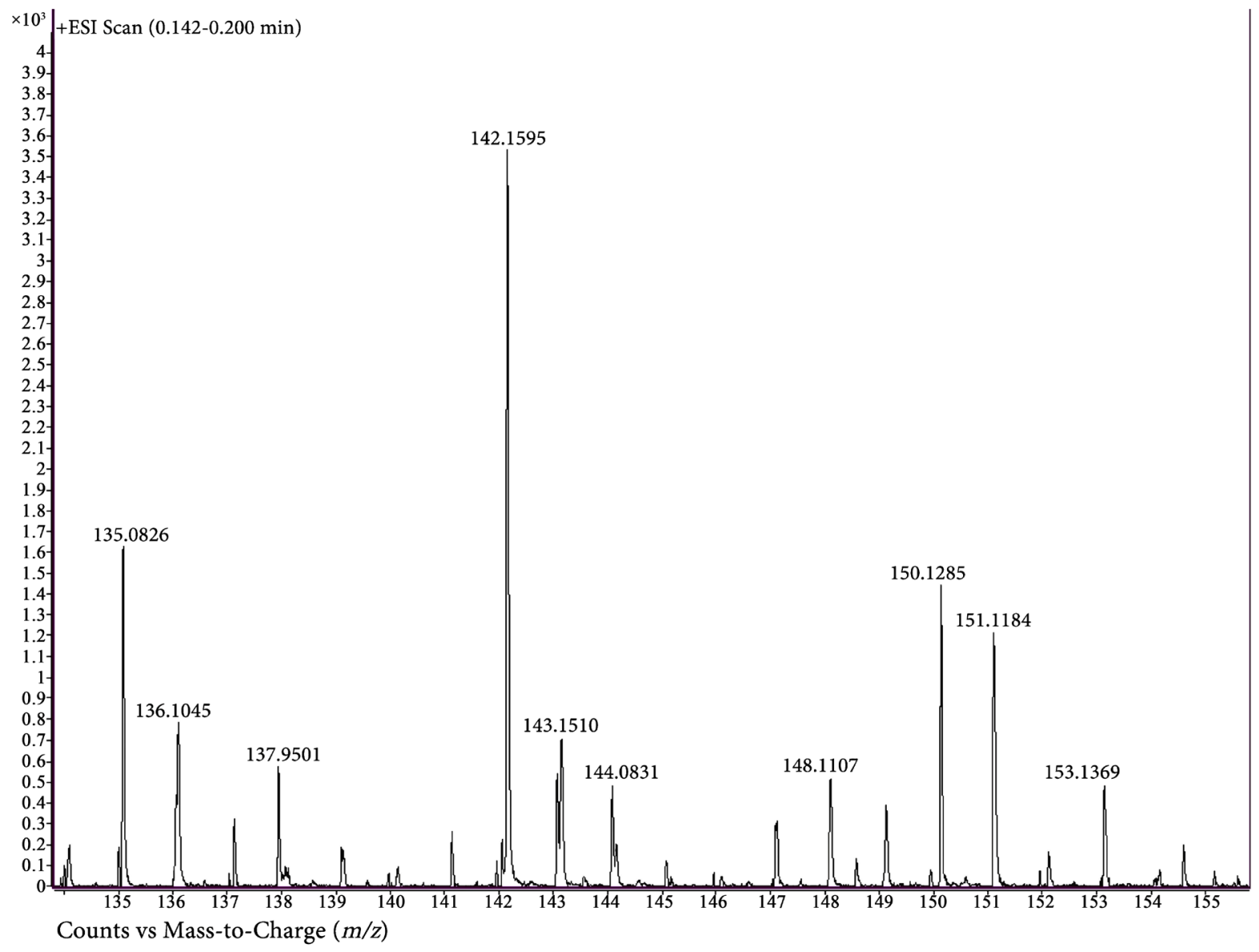

Figure 5. Accurate ESI-MS chromatogram, 133 - $160 \mathrm{~m} / \mathrm{z}$ range. 
LC-MS Analysis with ESI-EIC ( $m / z 139.6294$ - 143.7270) scan revealed mass spectra of signals: MS1 at $44.165-44.748 \mathrm{~min}$, MS2 at $44.698-45.298 \mathrm{~min}$ and MS3 at $47.197-47.847 \mathrm{~min}$, showing $\mathrm{m} / \mathrm{z}=142.1595$ as a fragment ion along with larger molecular ions (Figure 6).

To generate the possible molecular formulas from the monoisotopic mass [M $+\mathrm{H}]^{+}$ChemFinder software and virtual programs [29] [31] [32] were used. Generated for 142.1595, the first few formulas with the highest precision rates were: $\mathrm{C}_{9} \mathrm{H}_{20} \mathrm{~N}^{+}(-0.53 \mathrm{ppm}), \mathrm{C}_{8} \mathrm{H}_{8} \mathrm{~N}_{2}^{+} \quad(+87.95 \mathrm{ppm}), \mathrm{C}_{10} \mathrm{H}_{22}^{+} \quad(-88.98), \mathrm{C}_{9} \mathrm{H}_{18} \mathrm{O}^{+}$ $(+166.99)$ (the precision values are shown in brackets). We assume $[\mathrm{M}+\mathrm{H}]^{+}=$ $\mathrm{C}_{9} \mathrm{H}_{20} \mathrm{~N}^{+}$should correspond to the peak of interest; it might be related to or identical to the protonated imine of nonanal and has a matching precision rate within the acceptable $5 \mathrm{ppm}$ window, and could generate similar ion fragments as nonanal itself. We were not able to separate this unknown compound from the extract, as during the isolation attempts the component would degrade. We assume that this component could be an unstable intermediate produced by a

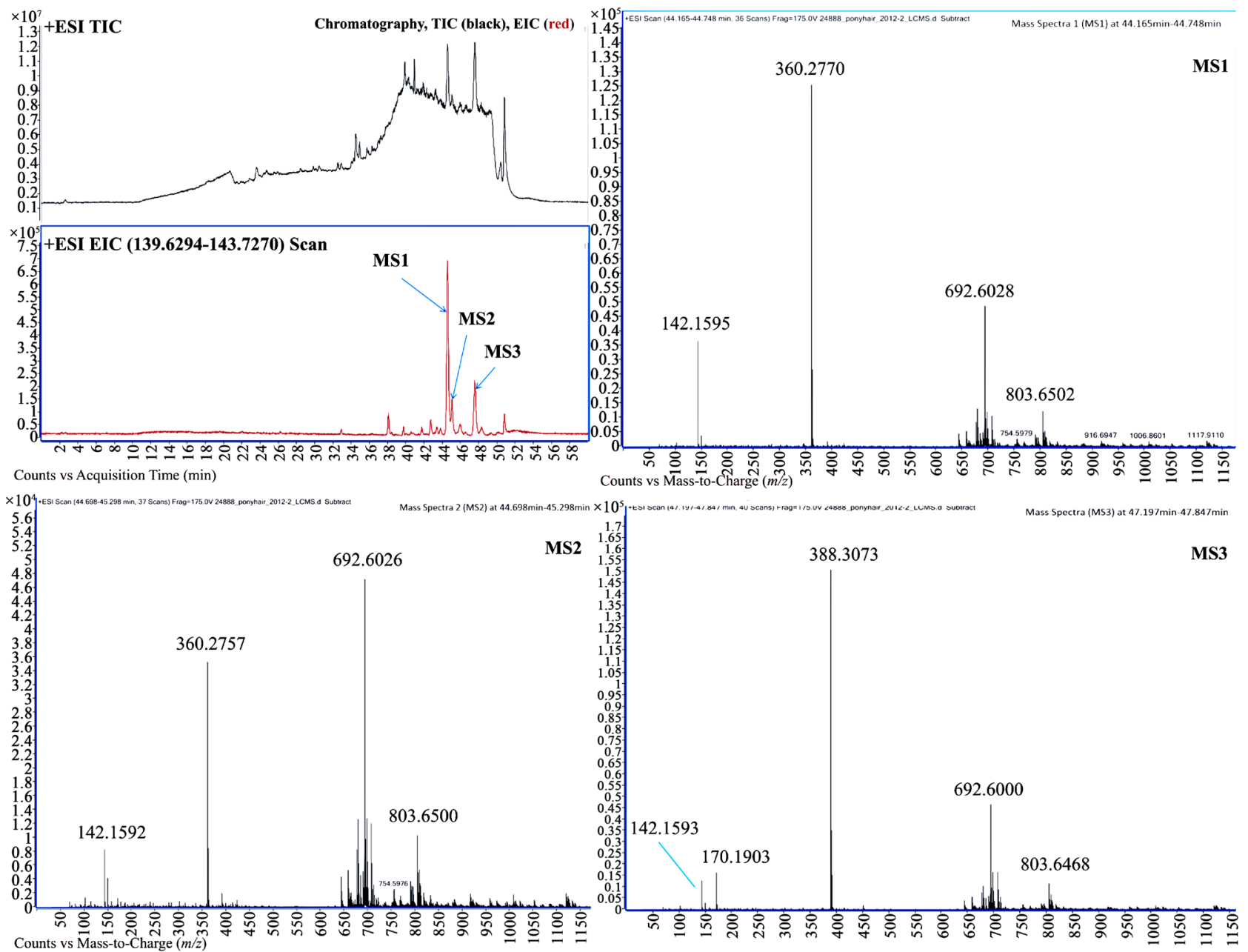

Figure 6. LC-MS chromatogram (ESI-EIC (red) taken from ESI-TIC (black) at $\mathrm{m} / \mathrm{z}$ values of 142 ); mass spectra of MS1 (44.165 $44.748 \mathrm{~min})$, MS2 (44.698 - $45.298 \mathrm{~min})$ and MS3 (47.197 - $47.847 \mathrm{~min})$ signals showing the ion of $\mathrm{m} / z 142 \mathrm{mass}$ amongst other major ions. 
fragmentation process. On the other hand, the occurrence of the ion with $m / z=$ 143 in the PICI spectrum is puzzling as it should either correspond to the radical cation derived from nonylamine, the mode of formation of which from an iminium ion under PICI conditions is unclear or it corresponds to the protonated form of nonanal, the occurrence of which can only be explained by an oxidative or hydrolytic process from the imine or iminium ion, uncommon in mass spectrometry.

\section{Conclusion}

In summary, while investigating the volatiles of the horse and pony hairs, we observed the unknown component, which in some cases gave a predominant peak by GC-MS spectroscopy at AI $=1067$ and RRI $=1550$. This peak had almost similar to nonanal mass fragmentation pattern but different retention time. Analysis by GC-FID with GC-MS, confirmed the same unknown peak. To identify the molecular ion, GC-MS with negative- and positive-ion chemical ionization methods was used. We observed the possible molecular ion with $\mathrm{m} / \mathrm{Z}=142$ for this unknown component. CEI-GC-MS Analysis of the sample derivatized with the acetic anhydride confirmed the molecular ion. For further studies ESI-MS and LC-MS spectroscopy methods were used. If the monoisotopic mass $\mathrm{m} / \mathrm{z}=$ 142.1595 observed by ESI-MS corresponds to the unknown peak, then $[\mathrm{M}+\mathrm{H}]^{+}=$ $\mathrm{C}_{9} \mathrm{H}_{20} \mathrm{~N}^{+}$could be the formula of the pseudomulecular ion, which hints towards the imine of nonanal $\left(\mathrm{C}_{9} \mathrm{H}_{19} \mathrm{~N}\right)$. With the aid of LC-MS techniques, we also observed series of higher molecular weight compounds. The determination of the molecular structure of these compounds along with our unknown component of the interest could be the subject for further investigation.

\section{Acknowledgements}

Dr. Jerome A. Hogsette (USDA-ARS, CMAVE, Gainesville, FL, USA), Dr. Paul Weldon (Smithsonian Conservation Biology Institute, National Zoological Park, Front Royal, VA, USA) for their support and suggestions, and UF/IFAS Department of Animal Sciences, University of Florida, Gainesville, FL, USA, for collection of horse and pony hairs; Mass Spectrometry Research and Education Center, University of Florida, Gainesville, FL, USA; Dr. Christopher Kampf (Johannes Gutenberg-Universität Mainz, Germany) for mass spectrometry.

\section{Funding}

This work was supported by the Deployed War-Fighter Protection Research Program and funded by the United States Department of Defense through the Armed Forces Pest Management Board, Agreement 60-0208-4-001 and under USDA Specific Cooperative Agreements 58-0208-0-068 and 58-0208-5-001. Financial support through the Rhineland Palatinate Center for Natural Products Research is gratefully acknowledged. 


\section{Dedication}

This work is dedicated in honor of Dr. Ulrich Bernier's retirement on July 7, 2019.

\section{Conflicts of Interest}

The authors declare no conflicts of interest regarding the publication of this paper.

\section{References}

[1] Tam, T.L., Hogsette, J. and TenBroeck, S. (2019) Can Attractive Sticky Traps Be Used to Protect Horses from the Bites of Stomoxys calcitrans (L.) (Diptera: Muscidae). Journal of Economic Entomology, 112, 2469-2473. https://doi.org/10.1093/jee/toz134

[2] Mullens, B.A. (2019) Horse Flies and Deer Flies (Tabanidae). In: Mullen, G.R. and Durden, L.A., Eds., Medical and Veterinary Entomology, 3rd Edition, Academic Press, Cambridge, 327-343. https://doi.org/10.1016/B978-0-12-814043-7.00016-9

[3] Nicolaides, N. (1974) Skin Lipids: Their Biochemical Uniqueness. Science (New York, N.Y.), 186, 19-26. https://doi.org/10.1126/science.186.4158.19

[4] Nicolaides, N. and Wells, G.C. (1957) On the Biogenesis of the Free Fatty Acids in Human Skin Surface Fat. Journal of Investigative Dermatology, 29, 423-433. https://doi.org/10.1038/jid.1957.118

[5] Wheatley, V.R. (1954) Studies of Sebum. 5. The Composition of Some Sebum-Like Materials of Human Origin. Biochemical Journal, 58, 167-172. https://doi.org/10.1042/bj0580167

[6] Nikkari, T. (1965) Composition and Secretion of the Skin Surface Lipids of the Rat; Effects of Dietary Lipids and Hormones. Scandinavian Journal of Clinical and Laboratory Investigation, 17, 1-140.

[7] Wheatley, V.R. and James, A.T. (1957) Studies of Sebum. 7. The Composition of the Sebum of Some Common Rodents. Biochemical Journal, 65, 36-42.

https://doi.org/10.1042/bj0650036

[8] Nikkari, T. (1969) The Occurrence of Diester Waxes in Human Vernix Caseosa and in Hair Lipids of Common Laboratory Animals. Comparative Biochemistry \& Physiology, 29, 795-803. https://doi.org/10.1016/0010-406X(69)91630-2

[9] Downing, D.T., Kranz, Z.H. and Murray, K.E. (1960) Studies in Waxes. XIV. An Investigation of the Aliphatic Constituents of Hydrolyzed Wool Wax by Gas Chromatography. Australian Journal of Chemistry, 13, 80-94. https://doi.org/10.1071/CH9600080

[10] Downing, D.T., Strauss, J.S. and Pochi, P.E. (1969) Variability in the Chemical Composition of Human Skin Surface Lipids. Journal of Investigative Dermatology, 53, 322-327. https://doi.org/10.1038/jid.1969.157

[11] Haahti, E. (1961) Major Lipid Constituents of Human Skin Surface with Special Reference to Gas-Chromatographic Methods. Scandinavian Journal of Clinical and Laboratory Investigation, 13, 1-108.

[12] Nikkari, T. (1974) Comparative Chemistry of Sebum. Journal of Investigative Dermatology, 62, 257-267. https://doi.org/10.1111/1523-1747.ep12676800

[13] Nicolaides, N., Fu, H.C. and Ansari, M.N.A. (1970) Diester Waxes in Surface Lipids of Animal Skin. Lipids, 5, 299-307. https://doi.org/10.1007/BF02531461

[14] Chatt, A. and Katz, S.A. (1989) Hair Analysis: Applications in the Biomedical and Environmental Sciences. VCH Publishers, New York. 
https://doi.org/10.1016/S0003-2670(00)81917-0

[15] Stewart, M.E. and Downing, D.T. (1991) Chemistry and Function of Mammalian Sebaceous Lipids. Advances in Lipid Research, 24, 263-301.

https://doi.org/10.1016/B978-0-12-024924-4.50013-4

[16] Wertz, P.W. and Downing, D.T. (1988) Integral Lipids of Human Hair. Lipids, 23, 878-881. https://doi.org/10.1007/BF02536208

[17] Downing, D.T. (1976) Mammalian Waxes. In: Kolattukudy, P.E., Ed., Chemistry and Biochemistry of Natural Waxes, Elsevier, Amsterdam, 17-48.

[18] Ishii, H., Krane, S., Itagaki, Y., Berova, N., Nakanishi, K. and Weldon, P.J. (2004) Absolute Configuration of a Hydroxyfuranoid Acid from the Pelage of the Genus Bos, 18-(6S,9R,10R)-Bovidic Acid. Journal of Natural Products, 67, 1426-1430. https://doi.org/10.1021/np049937u

[19] Colton, S.W. and Downing, D.T. (1983) Variation in Skin Surface Lipid Composition among the Equidae. Comparative Biochemistry \& Physiology, Part B: Biochemistry \& Molecular Biology, 75, 429-433. https://doi.org/10.1016/0305-0491(83)90353-X

[20] Scott, D.W. and Miller, W.H. (2010) Equine Dermatology. 2nd Edition, Elsevier Health Sciences, Amsterdam.

[21] Nicolaides, N., Fu, H.C. and Rice, G.R. (1968) The Skin Surface Lipids of Man Compared with Those of Eighteen Species of Animals. Journal of Investigative Dermatology, 51, 83-89. https://doi.org/10.1038/jid.1968.96

[22] Downing, D.T. and Colton, S.W. (1980) Skin Surface Lipids of the Horse. Lipids, 15, 323-327. https://doi.org/10.1007/BF02533547

[23] Ferreira, L.L., Sarria, A., de Oliveira Filho, J.G., de Silva, F.O., Powers, S.J., Caulfield, J.C., Pickett, J.A., Birkett, M.A. and Borges, L. (2019) Identification of a NonHost Semiochemical from Tick-Resistant Donkeys (Equus asinus) against Amblyomma sculptum Ticks. Ticks and Tick-Borne Diseases, 10, 621-627. https://doi.org/10.1016/j.ttbdis.2019.02.006

[24] Wertz, P.W. (2018) Naturally Occurring $\omega$-Hydroxyacids. International Journal of Cosmetic Science, 40, 31-33. https://doi.org/10.1111/ics.12432

[25] Blau, K. and Halket, J. (1993) Handbook of Derivatives for Chromatography. 2nd Edition, John Wiley \& Sons, New York, 327-343.

[26] Adams, R.P. (2007) Identification of Essential Oil Components by Gas Chromatography/Mass Spectrometry. 4th Edition, Allured Publ., Carol Stream.

[27] Curvers, J., Rijks, J., Cramers, C., Knauss, K. and Larson, P. (1985) Temperature Programmed Retention Indexes: Calculation from Isothermal Data. Part 1: Theory. Journal of High Resolution Chromatography, 8, 607-610. https://doi.org/10.1002/jhrc.1240080926

[28] McLafferty, F.W. and Stauffer, D.B. (1989) The Wiley/NBS Registry of Mass Spectral Data. J Wiley and Sons, New York.

[29] Hochmuth, D.H. (2008) MassFinder 4.0. Hochmuth Scientific Consulting, Hamburg.

[30] ESO 2000 (1999) The Complete Database of Essential Oils, Boelens Aroma Chemical Information Service. The Netherlands.

[31] MF FINDER. http://www.chemcalc.org/mf finder

[32] Find a Molecular Formula Based on a Monoisotopic Mass.

http://www.cheminfo.org/Spectra/Mass/MF from monoisotopic mass and PubC hem/index.html 